\title{
Tandem Synthesis of Ultra-High Molecular Weight Drag Reducing Poly- $\alpha$-Olefins for Low-Temperature Pipeline Transportation
}

\author{
Ilya E. Nifant'ev ${ }^{1,2, *(1)}$, Alexander N. Tavtorkin ${ }^{1}$, Alexey A. Vinogradov ${ }^{2}$, Sofia A. Korchagina ${ }^{1}$, \\ Maria S. Chinova ${ }^{1}$, Roman S. Borisov ${ }^{1}$, Grigory A. Artem' ${ }^{2}{ }^{3}$ and Pavel V. Ivchenko ${ }^{1,2}$ (D) \\ 1 A.V. Topchiev Institute of Petrochemical Synthesis RAS, 29 Leninsky Pr., 119991 Moscow, Russia; \\ tavtorkin@yandex.ru (A.N.T.); korchagina@ips.ac.ru (S.A.K.); chinova@yandex.ru (M.S.C.); \\ borisov@ips.ac.ru (R.S.B.); phpasha1@yandex.ru (P.V.I.) \\ 2 Chemistry Department, M.V. Lomonosov Moscow State University, 1-3 Leninskie Gory, \\ 119991 Moscow, Russia; vinasora@gmail.com \\ 3 I.Ya. Postovsky Institute of Organic Synthesis, Ural Division of RAS, 22/20 Kovalevskoy Str., \\ 620137 Yekaterinburg, Russia; griga1972@mail.ru \\ * Correspondence: ilnif@yahoo.com
}

Citation: Nifant'ev, I.E.; Tavtorkin, A.N.; Vinogradov, A.A.; Korchagina, S.A.; Chinova, M.S.; Borisov, R.S.; Artem'ev, G.A.; Ivchenko, P.V. Tandem Synthesis of Ultra-High Molecular Weight Drag Reducing Poly- $\alpha$-Olefins for Low-Temperature Pipeline Transportation. Polymers 2021, 13, 3930. https://doi.org/ $10.3390 /$ polym 13223930

Academic Editor: Asterios (Stergios) Pispas

Received: 26 October 2021 Accepted: 12 November 2021 Published: 14 November 2021

Publisher's Note: MDPI stays neutral with regard to jurisdictional claims in published maps and institutional affiliations.

Copyright: (c) 2021 by the authors. Licensee MDPI, Basel, Switzerland. This article is an open access article distributed under the terms and conditions of the Creative Commons Attribution (CC BY) license (https:/ / creativecommons.org/licenses/by/ $4.0 /)$.

\begin{abstract}
Ultra-high molecular weight poly- $\alpha$-olefins are widely used as drag reducing agents (DRAs) for pipeline transportation of oil and refined petroleum products. The synthesis of polyolefin DRAs is based on low-temperature Ziegler-Natta $(\mathrm{ZN})$ polymerization of higher $\alpha$-olefins. 1-Hexene based DRAs, the most effective at room temperature, typically lose DR activity at low temperatures. The use of 1-hexene copolymers with $\mathrm{C} 8-\mathrm{C} 12$ linear $\alpha$-olefins appears to offer a solution to the problem of low-temperature drag reducing. The present work aims to develop two-stage synthesis of polyolefin DRAs that is based on selective oligomerization of ethylene in the presence of efficient chromium/aminodiphosphine catalysts (Cr-PNP), followed by polymerization of the olefin mixtures, formed at oligomerization stage, using efficient titanium-magnesium ZN catalyst. We have shown that oligomerization of ethylene in $\alpha$-olefin reaction media proceeds faster than in saturated hydrocarbons, providing the formation of 1-hexene, 1-octene, and branched C10 and C12 olefins; the composition and the ratio of the reaction products depended on the nature of PNP ligand. Oligomerizates were used in $\mathrm{ZN}$ polymerization 'as is', without additional treatment. Due to branched character of $\mathrm{C} 10+$ hydrocarbons, formed during oligomerization of ethylene, resulting polyolefins demonstrate higher low-temperature DR efficiency at low polymer concentrations ( 1 ppm) in comparison with benchmark polymers prepared from the mixtures of linear $\alpha$-olefins and from pure 1-hexene. We assume that faster solubility and more efficient solvation of the polyolefins, prepared using 'tandem' ethylene-based process, represent an advantage of these type polymers over conventional poly(1-hexene) and linear $\alpha$-olefin-based polymers when used as 'winter' DRAs.
\end{abstract}

Keywords: chromium PNP catalysts; drag reducing; ethylene oligomerization; internal donor; linear $\alpha$-olefins; branched $\alpha$-olefins; polymerization; UHMW polyolefins; Ziegler-Natta catalysts

\section{Introduction}

The development of the energy-saving transportation and waste-free technologies are priority tasks for contemporary applied and fundamental science. To reduce pumping power and increase piping system capacity, modern pipeline transportation of crude oil and petroleum products use drag reducing agents (DRAs) comprised of ultra-high molecular weight (UHMW) polymers [1-3]. The drag reducing (DR) phenomena in dilute solutions of UHMW polymers was discovered by Toms [4] and subsequently studied by other scientists [5-11]. Hydrocarbon soluble UHMW poly- $\alpha$-olefins are widely applied as DRAs [12-14]. Since the DR effect increases as the length of the macromolecule 
grows [14-17], the main task in the synthesis of poly- $\alpha$-olefin DRAs is to achieve the highest possible degrees of polymerization $\left(D P_{n}\right)$.

Until quite recently, poly- $\alpha$-olefin DRAs production used bulk polymerization of $\alpha$-olefins, such as 1-hexene, 1-octene, 1-decene and 1-dodecene, in the presence of ZieglerNatta catalysts [13]. Hydrocarbon solutions of UHMW polyolefins have an extremely high viscosity, the increase in viscosity during the reaction hampers $\alpha$-olefin diffusion, hinders heat transfer and provokes a chain termination. As a result, in bulk polymerization the molecular weight of the polymer decreases at high monomer conversions [13,14,18-20], that is why the use of highly active and ultra-dispersed $\mathrm{ZN}$ catalysts and subzero reaction temperatures are required.

At room temperatures, UHMW poly(1-hexene) represent a best choice among other poly- $\alpha$-olefin DRAs due to the highest mass efficiency (the longest polymer chain for equal MW) and satisfactory solubility in hydrocarbons; homopolymers of higher $\alpha$-olefins (1-octene, 1-decene, etc.) have substantially lower DR efficiency in comparison with poly(1hexene) [21,22]. However, the DR efficiency of poly(1-hexene)s is falling rapidly with the decreasing temperature of the hydrocarbon fluid [23]. As mentioned in the patent literature [24-26], the formulations of "winter" DRAs are based on copolymers of 1-hexene with higher $\alpha$-olefins.

To a first approximation, the products of selective trimerization of ethylene, catalyzed by aminodiphosphine chromium complexes (Cr-PNP), represent comonomer mixtures with desirable 1-hexene / $\alpha$-olefin ratios $[27,28]$ (Scheme 1). Oligomerization of ethylene, catalyzed by Cr-PNP, was previously conducted in saturated hydrocarbons or in aromatic solvents [29-34]. We proposed that the use of the $\alpha$-olefins instead of conventional hydrocarbon solvents at the stage of ethylene oligomerization will provide 1-hexene enriched mixtures of terminal olefins that can be used in the synthesis of UHMW polymers 'as is', without any pre-treatment.
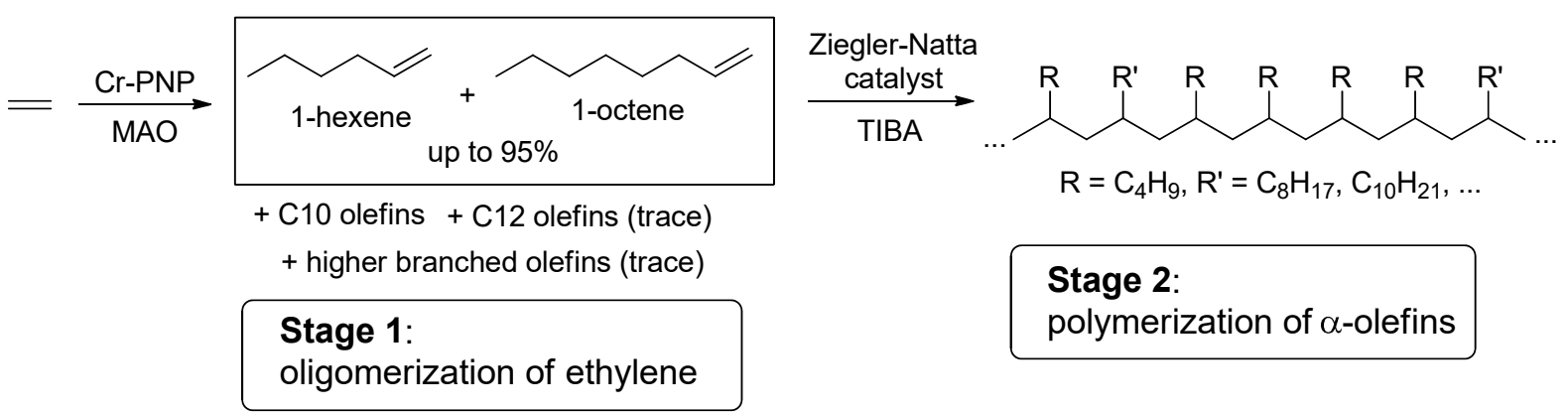

\section{Stage 2:}

polymerization of $\alpha$-olefins

Scheme 1. Tandem ethylene-based approach to UHMW poly- $\alpha$-olefins.

In the present work, we found that the activity of Cr-PNP catalysts in $\alpha$-olefins is substantially higher than in saturated hydrocarbons. By the use of two Cr-PNP catalysts with different $\mathrm{C} 6 / \mathrm{C} 8$ selectivity, we prepared the mixtures of the oligomers, analyzed their composition, and synthesized UHMW polyolefins. Copolymers were also prepared from the mixtures of linear $\alpha$-olefins with the same comonomer ratios. The results of the comparative studies of the DR efficiency of copolymers and benchmark poly(1-hexene) having the same MW are also presented and discussed.

\section{Materials and Methods}

\subsection{Solvents and Reagents}

Most of the solvents and chemicals were supplied by Merck (Darmstadt, Germany). 1-Hexene (97\%), 1-octene (98\%), 1-decene (94\%), 1-dodecene (95\%), n-pentane (95\%) and $n$-heptane $(95 \%)$ were dried over sodium and distilled before use under argon atmosphere. Toluene $(99.5 \%)$, diethyl ether $\left(\mathrm{Et}_{2} \mathrm{O}, \geq 99 \%\right)$ and tetrahydrofuran (THF, $\left.\geq 99 \%\right)$ were refluxed over sodium/benzophenone ketyl and distilled. $\mathrm{TiCl}_{4}(99.5 \%)$ was distilled before use and stored in polytetrafluoroethylene (PTFE) capped vessels. Ethanol (EtOH, $\geq 99 \%)$ 
was refluxed over Mg turnings ( $\geq 99.8 \%$ ) and distilled. Dimethyl sulfate ( $\geq 99 \%)$, methyl iodide ( $99 \%$ ), formaldehyde (37\% aq. solution), 2-ethylhexanal $(96 \%), \mathrm{NH}_{4} \mathrm{Cl}(\geq 99.5 \%)$, dimethyl sulfoxide (DMSO, $\geq 99.7 \%$ ), hexadecyltrimethylammonium chloride (50\% solution in 2-propanol/water 3:2), triisobutylaluminium (TIBA, 1M solution in hexane), trimethylaluminium (TMA, 2M solution in toluene), modified methylalumoxane (MMAO$12,1.2 \mathrm{M}$ solution in toluene), chromium (III) acetylacetonate $\left(\mathrm{Cr}(\mathrm{acac})_{3}, 99.99 \%\right.$ trace metal basis), and methanol (99.8\%) were used as purchased. Ethylene (99.999\%, Linde Gas, Russian Federation) was used without purification.

Diphosphine ligands N-(bis(2-methoxyphenyl)phosphino)-1,1-bis(2-methoxy-phenyl)$\mathrm{N}$-methylphosphinamine (L1) [30] and 5-(bis(2-methoxyphenyl)-phosphino)-6-(2-methoxyphenyl)-5,6-dihydrodibenzo[c,e][1,2]azaphosphinine (L2) [35] were synthesized according to the published procedures.

\subsection{Analysis}

The ${ }^{1} \mathrm{H}$ and ${ }^{13} \mathrm{C}\left\{{ }^{1} \mathrm{H}\right\}$ NMR spectra were recorded on a Bruker AVANCE 400 spectrometer (400 MHz, Bruker Corporation, Billerica, MS, USA) at $20^{\circ} \mathrm{C}$ (organic compounds) and at $50{ }^{\circ} \mathrm{C}$ (polymer samples). $\mathrm{CDCl}_{3}$ (D $99.8 \%$, Cambridge Isotope Laboratories, Inc., Tewksbury, MS, USA) was used as purchased. Polymer solutions for spectral study were prepared by $6-12 \mathrm{~h}$ dissolution of polymer samples $(3-5 \mathrm{mg})$ in $\mathrm{CDCl}_{3}(0.7 \mathrm{~mL})$ at $50{ }^{\circ} \mathrm{C}$ with stirring. The chemical shifts are reported relative to the solvent residual peaks $\left(\delta=7.26 \mathrm{ppm}\right.$ for ${ }^{1} \mathrm{H}$ and 77.16 for ${ }^{13} \mathrm{C}\left\{{ }^{1} \mathrm{H}\right\}$ NMR spectra).

Elemental analysis (C, H, N, O) was performed using a Perkin Elmer Series II CHNS/O Analyzer 2400 (Perkin Elmer, Waltham, MS, USA).

GC analysis was performed on a KRISTALL-2000M gas chromatograph (Chromatec, Yoshkar-Ola, Russian Federation) equipped with a SolGel-1ms $(60 \mathrm{~m} \times 0.25 \mathrm{~mm} \times 0.25 \mu \mathrm{m})$ column and a flame ionization detector. Helium was used as the carrier gas at the rate of $1.364 \mathrm{~cm}^{3} / \mathrm{min}$ and with the split ratio of 73.3: 1 . The injection temperature was $250{ }^{\circ} \mathrm{C}$, and the column temperature was $100{ }^{\circ} \mathrm{C}$ within 5 min before increasing from $100{ }^{\circ} \mathrm{C}$ to $300{ }^{\circ} \mathrm{C}$ at a rate of $10^{\circ} \mathrm{C} / \mathrm{min}$.

GC $\times$ GC/MS-FID analysis was performed using Leco Pegasus ${ }^{\circledR}$ BT 4 D instrument (LECO Corp., St. Joseph, MI, USA) equipped with Agilent 7890A gas chromatograph (Agilent Technologies, Santa Clara, CA, USA) with an embedded second oven, a twostage cryomodulator, a flow splitter, a time-of-flight mass analyzer and a flame ionization detector. The gas chromatographic system included two columns (the first was Restek Rxi-5Sil $30 \mathrm{~m} \times 0.25 \mathrm{~mm} \times 0.25 \mu \mathrm{m}$, the second Restek Rxi-17Sil $1.7 \mathrm{~m} \times 0.10 \mathrm{~mm} \times 0.10 \mu \mathrm{m}$, Restek, Centre County, PA, USA) and was operated in temperature-programmed mode (initial temperature $40^{\circ} \mathrm{C}$ for two minutes, heating to $320^{\circ} \mathrm{C}$ at a rate of $10^{\circ} \mathrm{C} / \mathrm{min}$, holding for $5 \mathrm{~min}$, the temperature of the second oven and the modulator was maintained at a level of 10 and $20^{\circ} \mathrm{C}$ higher than the temperature of the first oven, respectively) using helium as a carrier gas. The MS instrument was operated in $70 \mathrm{eV}$ electron ionization mode using $100 \mathrm{~Hz}$ recording mode. The flame ionization detector temperature was $340^{\circ} \mathrm{C}$, hydrogen and air flow rates were $40 \mathrm{~cm}^{3} / \mathrm{min}$ and $450 \mathrm{~cm}^{3} / \mathrm{min}$, respectively. Analysis results were processed using the CromaTOF software (LECO Corp., St. Joseph, MI, USA), the analytes were identified using NIST 20 database (National Institute of Standards and Technology, Gaithersburg, MD, USA), the relative quantities were determined on the basis of FID data presuming equal response factors for all olefins.

Size exclusion chromatography (SEC) measurements were performed in THF $\left(40^{\circ} \mathrm{C}\right.$, flow rate $1 \mathrm{~mL} / \mathrm{min}$ ) using an 1260 Infinity II (Agilent Technologies, Santa Clara, CA, USA) integrated instrument equipped with a PLgel MIXED-C column $\left(2 \times 10^{2}-2 \times 10^{6} \mathrm{Da}\right)$, an autosampler, and an refractive index detector. The measurements were recorded with universal calibration according to a polystyrene standard. 


\subsection{Oligomerization Experiments}

Oligomerization experiments were conducted according to the method reported previously [35] in a Polyclave (Büchi AG, Uster, Switzerland) autoclave equipped with $1 \mathrm{~L}$ stainless steel reactor and fluidized jacket, connected to a thermostatic bath. Ethylene was added to the reaction through a mass flow controller. Solvents and reagents were introduced into the reactor using burettes, and a screw-type syringe was used for the injection of the catalyst solutions. The ethylene uptake data were recorded, along with the reactor pressure, and the reaction mixture temperature.

In a typical experiment, the rigorously cleaned autoclave was heated to $120^{\circ} \mathrm{C}$ under vacuum for $60 \mathrm{~min}$, and then cooled to reaction temperature and back-filled with ethylene (10 bar), which was then vented to 1 bar by septa to purge the inlet valve. Solvent ( $n$-heptane or $\alpha$-olefin, $120 \mathrm{~mL}$ ) and TMA ( $1.5 \mathrm{~mL}$ of $2 \mathrm{M}$ solution in toluene) were then added using an injection system. The autoclave was pressurized with ethylene to 10 bar, vented, pressurized to $30 \mathrm{bar}$, and heated to $50{ }^{\circ} \mathrm{C}$. On a Schlenk line, a catalyst solution was prepared by the reaction of $\mathrm{Cr}(\mathrm{acac})_{3}(30 \mu \mathrm{mol})$ with a PNP ligand $(40 \mu \mathrm{mol})$ in toluene $(4 \mathrm{~mL})$, followed by the addition of MMAO-12 $(5 \mathrm{~mL}, 1.2 \mathrm{M}$ solution in toluene, $\mathrm{Al} / \mathrm{Cr}=200$ ), and then stirred for $15 \mathrm{~min}$. The catalyst was transferred to the autoclave by syringe. The pressure was maintained at a constant value throughout the reaction by the continuous addition of ethylene, which was monitored using flowmeter. After a defined period of time, the gas supply was closed and the reactor cooled to $5{ }^{\circ} \mathrm{C}$ and carefully vented. The data on oligomerizate composition are presented and discussed in Section 3.1. The products of oligomerization with different hexene-1/octene-1 ratios M1 and M2 were selected for polymerization experiments. These samples were obtained using Cr-PNP catalysts, based on PNP ligands L1 and L2, respectively, in 1-hexene reaction media.

\subsection{Synthesis of New Internal Donor, 3,3-Bis(methoxymethyl)heptane (BMMH)}

\subsubsection{2-Butyl-2-ethylpropane-1,3-diol}

2-Ethylhexanal (120 g, $0.920 \mathrm{~mol})$ and formaldehyde (155 $\mathrm{g}$ of $37 \%$ aq. solution, $2.350 \mathrm{~mol})$ were placed into $500 \mathrm{~mL}$ flask. The solution of $\mathrm{NaOH}(92.7 \mathrm{~g}, 1.110 \mathrm{~mol})$ in $\mathrm{H}_{2} \mathrm{O}(100 \mathrm{~mL})$ was added dropwise with variable rates $(0.100 \mathrm{~mol} / \mathrm{h}$ during the first two hours, $0.150 \mathrm{~mol} / \mathrm{h}$ during $3 \mathrm{rd}$ and 4 th hours, and $0.220-0.250 \mathrm{~mol} / \mathrm{h}$ in the time remaining). The mixture was neutralized to neutral $\mathrm{pH}$ by the addition of conc. $\mathrm{H}_{2} \mathrm{SO}_{4}$ with stirring and intensive cooling. The organic layer was separated and distilled under reduced pressure (B. p. $\left.130-135^{\circ} \mathrm{C} / 8 \mathrm{mbar}\right)$. The yield $133.0 \mathrm{~g}(90 \%)$.

\subsubsection{2-Ethyl-2-(methoxymethyl)hexan-1-ol}

2-Butyl-2-ethylpropane-1,3-diol $(110 \mathrm{~g}, 0.690 \mathrm{~mol})$ was added dropwise at $60^{\circ} \mathrm{C}$ to the solution of $\mathrm{NaOH}(70 \mathrm{~g}, 1.750 \mathrm{~mol})$ in $\mathrm{H}_{2} \mathrm{O}(70 \mathrm{~mL})$. The mixture was cooled to $40-45^{\circ} \mathrm{C}$, and dimethyl sulfate $(95 \mathrm{~mL}, 1 \mathrm{~mol})$ was added within $2 \mathrm{~h}$, maintaining a temperature of $45-50{ }^{\circ} \mathrm{C}$. After $1 \mathrm{~h}$ of stirring, $\mathrm{H}_{2} \mathrm{O}(200 \mathrm{~mL})$ and hexane $(100 \mathrm{~mL})$ were added, organic layer was separated, aqueous layer was washed by hexane $(20 \mathrm{~mL})$. Combined organic phase was washed by water $(2 \times 20 \mathrm{~mL})$ and evaporated under reduced pressure. The residue was distilled collecting the fraction $90-110^{\circ} \mathrm{C} / 16 \mathrm{mbar}$. The yield $84.0 \mathrm{~g}(69.9 \%)$, colorless liquid containing 10\% of BMMH (for ${ }^{1} \mathrm{H}$ NMR spectrum, see Figure $\mathrm{S} 1$ in the Supplementary Materials). The synthesis was repeated twice, the yields were 83.5 and 83.8 $\mathrm{g}$ (69.4 and 69.7\%, respectively). Distillation residues were combined and dissolved in benzene $(100 \mathrm{~mL})$. Solution of $\mathrm{NaOH}(40 \mathrm{~g})$ in $\mathrm{H}_{2} \mathrm{O}(40 \mathrm{~mL})$, and hexadecyltrimethylammonium chloride solution $(0.5 \mathrm{~mL})$ were added. Dimethyl sulfate $(53 \mathrm{~mL}, 0.550 \mathrm{~mol})$ was added dropwise, maintaining a temperature of $45-50{ }^{\circ} \mathrm{C}$. After $1 \mathrm{~h}$ of stirring, the mixture was treated as described above, and additional amount of 2-ethyl-2-(methoxymethyl)hexan-1-ol $(37.4 \mathrm{~g}$ ) was obtained by distillation. The total yield of the product was $80 \%$. 


\subsubsection{3,3-Bis(methoxymethyl)heptane (BMMH)}

$\mathrm{NaH}(60 \%$ suspension in mineral oil, $25.0 \mathrm{~g}, 0.625 \mathrm{~mol})$ was placed in $500 \mathrm{~mL}$ flack, washed by hexane $(3 \times 50 \mathrm{~mL})$, and THF $(200 \mathrm{~mL})$ was added. The mixture of 2-butyl-2ethylpropane-1,3-diol (104 g, $0.600 \mathrm{~mol})$ and methyl iodide $(38.0 \mathrm{~mL}, 0.61 \mathrm{~mol})$ was added dropwise (the reaction begins after the addition of $\sim 5 \mathrm{~mL}$ of the mixture). After a slowdown of the release of hydrogen, the addition was continued with external cooling of the mixture $(\sim 4 \mathrm{~h})$. After conditioning during $12 \mathrm{~h}, \mathrm{H}_{2} \mathrm{O}(10 \mathrm{~mL})$ was added with caution. Organic phase was separated, the precipitate was dissolved in $\mathrm{H}_{2} \mathrm{O}(25 \mathrm{~mL})$, the solution was washed by hexane $(20 \mathrm{~mL})$. Combined organic phase was washed by water $(2 \times 20 \mathrm{~mL})$ and evaporated under reduced pressure. The residue was distilled collecting the fraction 95-100 ${ }^{\circ} \mathrm{C} / 13$ mbar. The yield $107 \mathrm{~g}(95 \%)$, colorless liquid. Elemental Analysis: for $\mathrm{C}_{11} \mathrm{H}_{24} \mathrm{O}_{2}$ calculated (\%): $\mathrm{C}, 70.16 ; \mathrm{H}, 12.85 ; \mathrm{O}, 16.99$; found (\%): $\mathrm{C}, 70.09 ; \mathrm{H}, 12.89 ; \mathrm{O}, 17.02$. ${ }^{1} \mathrm{H}$ NMR $\left(400 \mathrm{MHz}, \mathrm{CDCl}_{3}, 20{ }^{\circ} \mathrm{C}\right) \delta: 3.29(\mathrm{~s}, 6 \mathrm{H}) ; 3.14(\mathrm{~s}, 4 \mathrm{H}) ; 1.26\left(\mathrm{q},{ }^{3} \mathrm{~J}=7.5 \mathrm{~Hz}, 4 \mathrm{H}\right) ; 1.18$ $(\mathrm{m}, 4 \mathrm{H}) ; 0.88\left(\mathrm{t},{ }^{3} \mathrm{~J}=7.2 \mathrm{~Hz}, 3 \mathrm{H}\right) ; 0.78\left(\mathrm{t},{ }^{3} J=7.5 \mathrm{~Hz}, 3 \mathrm{H}\right) .{ }^{13} \mathrm{C}\{1 \mathrm{H}\} \mathrm{NMR}\left(101 \mathrm{MHz}, \mathrm{CDCl}_{3}\right.$, $\left.20{ }^{\circ} \mathrm{C}\right) \delta: 75.54 ; 59.34 ; 40.94 ; 31.03 ; 25.13 ; 24.05 ; 23.74 ; 14.29 ; 7.46$. NMR spectra of BMMH are presented in Figures S2 and S3 in the Supplementary Materials.

\subsection{Synthesis of Titanium-Magnesium Catalyst}

Titanium-magnesium catalyst (TMC) was obtained using the method reported previously [36] (type C2 catalyst in this article) with the replacement of the BMMP donor by BMMH donor and with substantial modifications of the experimental protocol. For details of the synthesis and analysis of TMC, see Section S1 in the Supplementary Materials.

\subsection{Polymerization Experiments}

\subsubsection{Preparation of Model Mixtures of Linear $\alpha$-Olefins}

Model mixtures M1c and M2c were prepared in a glove box by weighting of the calculated amounts of 1-hexene, 1-octene, 1-decene, 1-dodecene and toluene that correspond to the ratios of 1-hexene, 1-octene, C10, C12 olefins, and toluene in oligomerizates M1 and M2, respectively.

\subsubsection{Low-Temperature Polymerization}

1-Hexene, oligomerization product, or model mixture of linear $\alpha$-olefins $(20 \mathrm{~mL})$ was placed into $50 \mathrm{~mL}$ vial, TIBA $(0.4 \mathrm{~mL}$ of $1 \mathrm{M}$ solution in heptane) was added. The vial was cooled to $-40{ }^{\circ} \mathrm{C}$, TMC suspension $(8 \mu \mathrm{L}$, [Ti] $=0.16 \mathrm{M})$ was added with stirring, and the mixture was stored at $-12{ }^{\circ} \mathrm{C}$ within 10 days. The yields and characteristics of polymers $\mathbf{P H}, \mathbf{P 1}, \mathbf{P 1 c}, \mathbf{P 2}$, and P2c are presented and discussed in Section 3.3 and in Section S2 in the Supplementary Materials.

\subsection{Drag Reducing Experiments}

\subsubsection{Sample Preparation}

The sample of polymer $(0.250 \mathrm{~g})$ was dissolved with slow stirring (magnetic stirrer, $60 \mathrm{rpm}$ ) in $n$-heptane ( $200 \mathrm{~g}$ ) within $24 \mathrm{~h}$. The resulting viscous solutions having $1250 \mathrm{ppm}$ concentration $(1 \mathrm{~g})$ was taken and diluted by $n$-heptane $(49 \mathrm{~g})$ yielding $25 \mathrm{ppm}$ solution that was used for drag reducing tests after appropriate dilution.

\subsubsection{Capillary Turbulent Rheometry}

Drag reducing tests were performed using turbulent capillary rheometer (Reynolds number $1 \times 10^{4}$ for $n$-heptane) by flowing the samples of the polymer solution and pure solvent at given temperature and fixing expiration times for the solvent and polymer solutions. Drag reducing (DR) was calculated by the Equation (1).

$$
D R=\frac{\lambda_{0}-\lambda_{p}}{\lambda_{0}} \times 100 \%=\frac{t_{0}^{2}-t_{p}^{2}}{t_{0}^{2}} \times 100 \%
$$


where $\lambda_{0}$-the hydrodynamic drag coefficient of the solvent; $\lambda_{p}$-the hydrodynamic drag coefficient of the polymer solution; $t_{0}$-expiration time for the solvent; $t_{p}$-expiration time for polymer solution. The test was carried out three times for each sample of the polymer solution.

\section{Results and Discussion}

\subsection{The Main Idea of the Two-Stage Synthesis of Polyolefin DRAs}

Selective oligomerization of ethylene using chromium-diphosphine catalysts seems to be the most efficient synthetic approach to 1-hexene, 1-octene or 1-hexene/1-octene mixtures [30,37-41]. Logically, this reaction was used in tandem production of LLDPE, copolymers of ethylene and 1-hexene (or 1-octene) [42,43]. However, metallacyclic mechanism of ethylene oligomerization when using Cr-PNP catalysts [30,32,44-48] allows for the formation of significant amounts of $\mathrm{C} 10$ and $\mathrm{C} 12$ hydrocarbons via coordination/insertion of 1-hexene or 1-octene molecules instead of ethylene molecule in the course of the reaction. As a result, C10 (Scheme 2) and C12 olefins of branched molecular structure are formed $[27,28]$. The presence of higher branched $\alpha$-olefins allows us to consider such oligomerizates as prospective comonomer feedstocks for UHMW polyolefins. Therefore, two-stage ethylene-based synthesis of polyolefin DRAs (Schemes 1 and 2) seemed feasible.

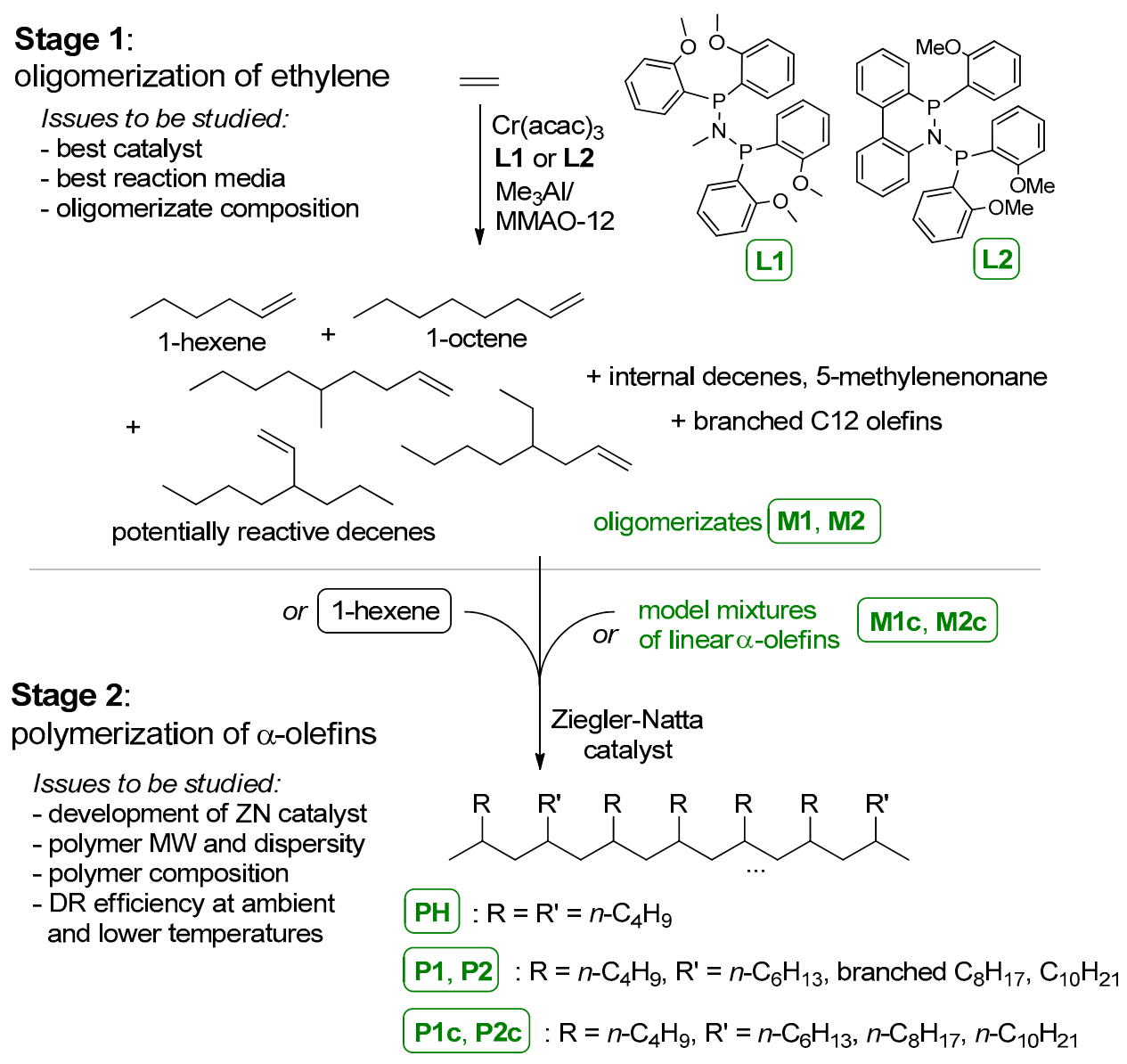

Scheme 2. Ethylene-based synthesis of polyolefin DRAs, studied in this work: scope and content.

\subsection{Oligomerization of Ethylene}

\subsubsection{The Use of $\alpha$-Olefins as a Reaction Media}

To assess the feasibility of this two-stage approach to polyolefin DRAs, we selected two diphosphine ligands, L1 [30] and L2 [35] (Scheme 2) for the preparation of Cr-PNP catalysts of the oligomerization stage, $\mathrm{Cr}-\mathbf{L} 1$ and $\mathbf{C r}-\mathbf{L} 2$, respectively. Hundreds of chromium diphosphine complexes have been explored to date $[32,34,37-41]$, but high (TOF up to $10^{6} \mathrm{~h}^{-1}$ ) 
and steady catalytic activity was demonstrated by one of the first Cr-PNP catalysts of selective trimerization of ethylene, Cr-L1 (Scheme 2) [30]. Recently we proposed novel type of 'constrained' diphosphine ligands, containing 5,6-dihydrodibenzo[c,e][1,2]azaphosphinine fragment, and demonstrated high activity of Cr-PNP catalyst Cr-L2 (Scheme 2) in oligomerization of ethylene [35].

In our previous comparative studies [35], we prepared Cr-L1 and Cr-L2 by the reaction of $\mathrm{Cr}(\mathrm{acac})_{3}$ with diphosphine ligands, followed by activation using MMAO12 and TMA. Both catalysts demonstrated close activities; however, Cr-L2 catalyzed tri/tetramerization with a formation of 1-hexene and 1-octene in $\sim 2: 1$ ratio by weight. In addition, both oligomerizates contained $\mathrm{C} 10$ and C12 olefins in visible amounts. Therefore, it seemed appropriate to use the products of ethylene oligomerization as a monomer mixture for the further polymerization in the presence of titanium-magnesium ZN catalyst.

However, there are two factors that complicate the immediate use of such oligomerizates in $\mathrm{ZN}$ polymerization. First, organoaluminum activators MMAO-12 and TMA are not consistent with ZN catalysts; the latter are activated preferably with TIBA. Therefore, minimal amounts of MMAO-12 and TMA should be used at the first stage. Second, even with the high activity of Cr-L1 and Cr-L2, the resulting reaction mixtures contain moderate (10-15\%) amounts of the inert solvents [35], which is completely unnecessary at the further polymerization stage due to polymer swelling.

In all experiments on Cr-PNP catalyzed oligomerization of ethylene described in the literature, the choice of the reaction media was limited by saturated hydrocarbons and aromatic solvents $[38,41,49-51]$. Given that $\alpha$-olefins are formed during ethylene oligomerization, we proposed that $\alpha$-olefins can be initially used as a reaction media, and made comparative experiments on ethylene oligomerization, catalyzed by $\mathbf{C r}-\mathbf{L 1}$, in $n$ heptane, 1-hexene, 1-octene, and 1-decene. In addition, we studied an opportunity to reduce the content of MMAO-12 and TMA (that may hamper further polymerization) and found appropriate $[\mathrm{Al}] /[\mathrm{Cr}]$ ratio of 200 for oligomerization stage. The results of our experiments under optimized conditions are presented visually in Figure 1.

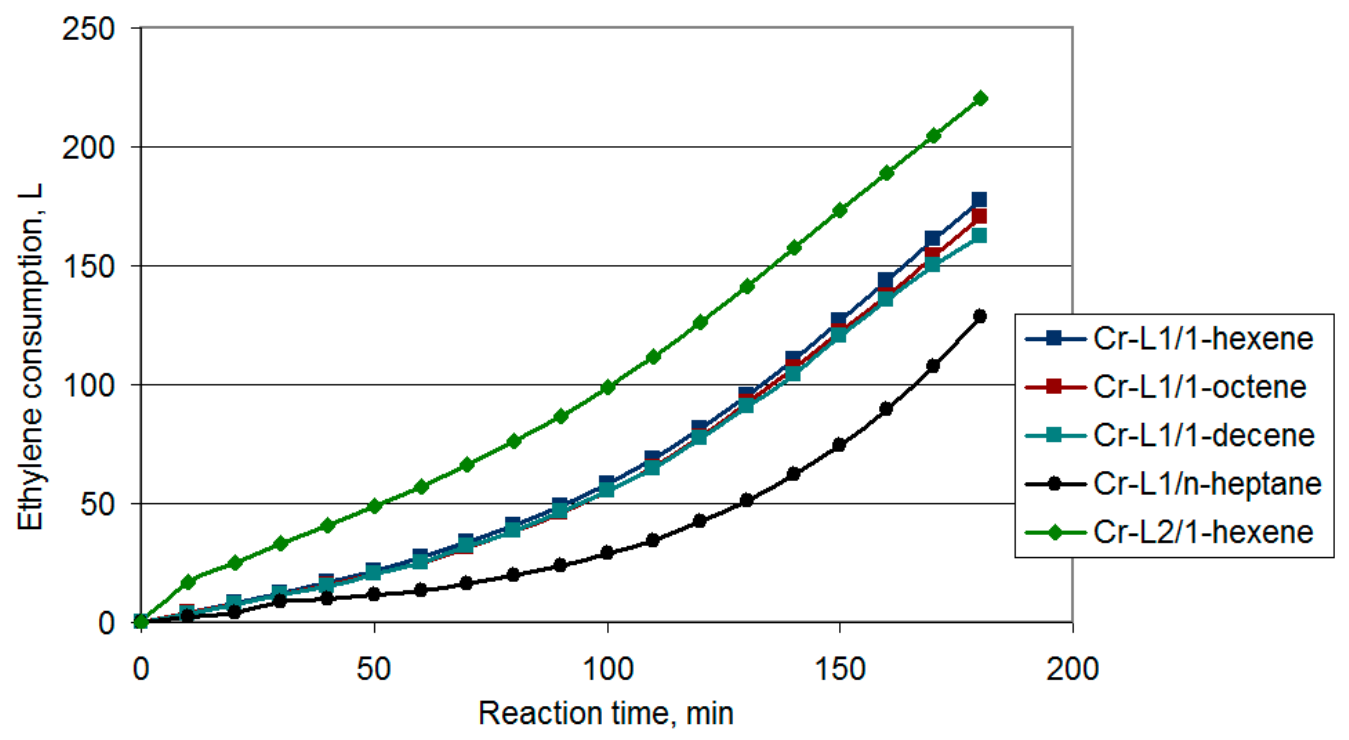

Figure 1. Ethylene consumption curves for ethylene oligomerization using Cr-PNP catalysts (Cr(acac) 3 ( $30 \mu \mathrm{mol}) / \mathrm{PNP}$ ligand $(40 \mu \mathrm{mol}))$ activated by MMAO- 12 at [Al]/[Cr] ratio of 200, $120 \mathrm{~mL}$ of the solvent, $\left.30 \mathrm{bar}, 50{ }^{\circ} \mathrm{C}\right)$.

As can be seen in Figure 1, Cr-L1 catalyzed oligomerization of ethylene in $\alpha$-olefin media proceeds considerably faster in comparison with oligomerization in $n$-heptane, the latter had been characterized by longer induction period. The rate of the reaction was essentially independent of the type of $\alpha$-olefin used (although the activity slightly decreased when moving from 1-hexene to 1-decene). Since 1-hexene is the most affordable 
and accessible higher $\alpha$-olefin, the experiment on Cr-L2 catalyzed oligomerization of ethylene was carried out in 1-hexene media, and Cr-L2 catalyst demonstrated much more higher activity in comparison with Cr-L1. The reaction products, obtained during ethylene oligomerization in 1-hexene, catalyzed by Cr-L1 and Cr-L2, have been chosen for the further studies of copolymerization as comonomer mixtures M1 and M2, respectively.

\subsubsection{Composition and Molecular Structure of the Oligomerization Products}

The mechanism of ethylene oligomerization when using Cr-PNP catalysts [30,32,44-48] allows for the formation of $\mathrm{C} 10$ and $\mathrm{C} 12$ hydrocarbons via coordination/insertion of 1hexene or 1-octene molecules instead of ethylene molecule in metallacyalic reaction intermediates. For $\mathrm{C} 10$ oligomerization products branched molecular structure was proposed and proved (Scheme 2, Table 1) [27,28].

Table 1. Compositions of the oligomerization products, model linear $\alpha$-olefin mixtures, and 1-hexene benchmark feedstock.

\begin{tabular}{|c|c|c|c|c|c|c|c|}
\hline \multirow{2}{*}{$\begin{array}{l}\text { Number of } \\
\text { C Atoms }\end{array}$} & \multirow{2}{*}{ Structure } & \multirow{2}{*}{ Name } & \multicolumn{5}{|c|}{ wt. \% of the Components } \\
\hline & & & $\mathbf{H}$ & M1 & M1c & M2 & M2c \\
\hline 6 & & 1-hexene & 97.9 & 74.4 & 74.4 & 47.2 & 47.2 \\
\hline 7 & & toluene & 2.1 & 2.1 & 2.1 & 2.1 & 2.1 \\
\hline 8 & & 1-octene & - & 10.4 & 10.4 & 25.1 & 25.1 \\
\hline 10 & & 4-vinyloctane & - & 2.9 & - & 5.1 & - \\
\hline 10 & & 4-ethyl-1-octene & - & 2.1 & - & 3.9 & - \\
\hline 10 & & 5-methyl-1-nonene & - & 4.5 & - & 9.6 & - \\
\hline 10 & & 5-methylenenonane & - & 1.6 & - & 1.9 & - \\
\hline 10 & & 1-decene & - & 0.2 & 11.6 & 0.2 & 21.0 \\
\hline 10 & & 5-decene & - & 0.1 & - & 0.1 & - \\
\hline 10 & & 4-decene & - & 0.2 & - & 0.2 & - \\
\hline 12 & - & C12 alkenes ${ }^{1}$ & - & 1.5 & $1.5^{2}$ & 4.6 & $4.6^{2}$ \\
\hline
\end{tabular}

${ }^{1}$ A complex mixture of the isomers. ${ }^{2}$ 1-Dodecene.

We made GC $\times$ GC/MS-FID analysis of the oligomerizates $\mathbf{M} 1$ and $\mathbf{M} 2$, selected for the further polymerization experiments (Table 1). The results of this analysis were in line with the data reported previously [27]. In particular, the main C10 component in oligomerizates M1 and M2 was 5-methyl-1-nonene (4.5 and $9.6 \mathrm{wt} . \%$, respectively). The combined share of two other marked components, 4-vinyloctane and 4-ethyl-1-octene, was found to be roughly the same. These products represent $\alpha$-olefins that are potentially reactive in $\mathrm{ZN}$ polymerization. The relative amounts of 1-decene in oligomerizates M1 and M2 were negligible, and the total relative content of the three remaining C10 reaction products, namely, 5-methylenenonane, 4-decene, and 5-decene, was found to be $\sim 0.5 \mathrm{wt} . \%$. Therefore, both oligomerizates $\mathbf{M} 1$ and $\mathbf{M} 2$ in their composition mainly contained $\alpha$-olefins potentially reactive in $\mathrm{ZN}$ polymerization.

\subsection{Optimization and Preparation of Titanium-Magnesium ZN Catalyst (TMC)}

3.3.1. Synthesis of Internal Donor BMMH

In our previous study, we showed that titanium-magnesium ZN catalyst (TMC), prepared by the reaction of $\mathrm{Mg}(\mathrm{OEt})_{2}$ with $\mathrm{TiCl}_{4}$ in toluene [52] in the presence of the 
latest generation of diether donor, 3,3-bis(methoxymethyl)pentane (BMMP) [36,53], demonstrated the best characteristics in $\alpha$-olefin polymerization [36]. However, the synthetic availability and cost of BMMP, synthesized from 2,2-diethylpropane-1,3-diol, focused us on the search of the more synthetically accessible donors. As a result of our studies, an alternative donor with the same characteristics, namely, 3,3-bis(methoxymethyl)heptane (BMMH), had been chosen. This donor was previously used in propylene polymerization $[54,55]$ but still had not been appropriately characterized as new organic compound, as it is in the present paper (see Section 2.4.2).

The synthesis of BMMH is based on the reaction of 2-ethylhexanal with formaldehyde (aldol and Cannizzaro reactions) followed by alkylation in a similar way to the method proposed by Agnes and Borsotti [56,57]. The yield of the intermediate diol was almost quantitative; however, double alkylation failed ( $\sim 60 \%$ yield), and the total yield of $76 \%$ was obtained when two-stage alkylation was used (Scheme 3).

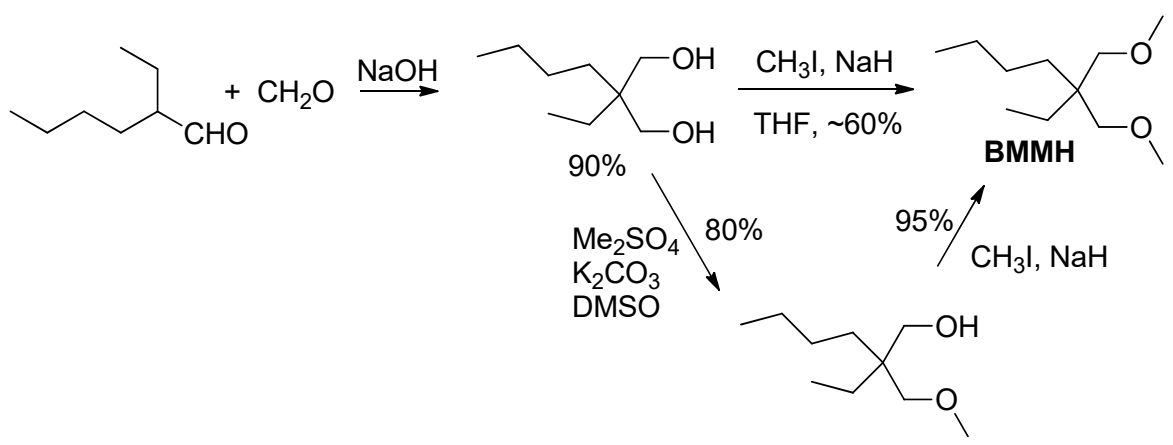

Scheme 3. Synthesis of internal donor 3,3-bis(methoxymethyl)heptane (BMMH).

\subsubsection{Synthesis of TMC}

In our further development of TMC, targeted on the synthesis of $\alpha$-olefin copolymers, we explored the potential of the method reported in [36]. This method was based on the addition of $\mathrm{TiCl}_{4}$ and then BMMP to suspension of $\mathrm{Mg}(\mathrm{OEt})_{2}$. To obtain the catalyst with highest productivity, we studied the sequence of the reagent mixing, and found that the most active TMC can be obtained by the addition of the $\mathrm{Mg}(\mathrm{OEt})_{2}$ suspension to excess of $\mathrm{TiCl}_{4}$, followed by the addition of BMMH. For details of the experiments on optimization of the synthesis of TMC and comparative catalytic experiments, see Section S1 in the Supplementary Materials.

\subsection{Polymerization and Polymer Analysis}

Polymerization Experiments

To prepare benchmark UHMW poly(1-hexene), we carried out bulk polymerization of 1-hexene, containing calculated amount of toluene, at $-12{ }^{\circ} \mathrm{C}$. After 10 days, $97 \%$ conversion was detected with the obtaining of homopolymer PH. This method was also used in the synthesis of copolymers P1-P2c, and due to high activity of TMC (see Section S1.3 in the Supplementary Materials), high polymer yields were achieved after 10 days (Table 2).

Table 2. The results of polymerization experiments.

\begin{tabular}{|c|c|c|c|c|c|c|c|}
\hline \multirow{2}{*}{ Polymer } & \multirow{2}{*}{ Yield, \% } & \multirow{2}{*}{$M_{\mathrm{p}}, \times 10^{6} \mathrm{Da}^{1}$} & \multirow{2}{*}{$M_{\mathrm{n}}, \times 10^{6} \mathrm{Da}^{1}$} & \multirow{2}{*}{$\bigoplus_{M}{ }^{1}$} & \multicolumn{3}{|c|}{ Comonomer Molar Ratio ${ }^{2}$} \\
\hline & & & & & C6 & $\mathrm{C} 8$ & C10 \\
\hline PH & 97 & 4.21 & 1.94 & 2.31 & $100 / 100$ & - & - \\
\hline P1 & 91 & 4.74 & 3.23 & 1.61 & $85 / 84.6$ & $8 / 8.7$ & $3 / 7.8$ \\
\hline P1c & 95 & 4.32 & 2.00 & 2.31 & $83 / 83.4$ & 8/8.9 & $6 / 7.8$ \\
\hline P2 & 89 & 4.92 & 2.42 & 1.55 & $61 / 61.2$ & $20 / 24.4$ & $9 / 14.5$ \\
\hline P2c & 97 & 5.45 & 1.87 & 2.91 & $60 / 60.0$ & $24 / 23.9$ & $16 / 16.0$ \\
\hline
\end{tabular}

${ }^{1} \mathrm{SEC}$ data (THF, polystyrene standard). ${ }^{2}$ A rough estimation by integration of the signals in ${ }^{13} \mathrm{C}\left\{{ }^{1} \mathrm{H}\right\} \mathrm{NMR}$ spectra/calculated on the basis of $\alpha$-olefin ratios in mixtures M1-M2c. 
Benchmark poly(1-hexene) (PH) and copolymers (P1, P1c, P2, P2c) had $M_{\mathrm{p}}$ in the range 4.2-5.5 $\times 10^{6} \mathrm{Da}$. The values of $M_{\mathrm{n}}\left(3.2 \times 10^{6} \mathrm{Da}\right.$ for P1 and $2 \times 10^{6} \mathrm{Da}$ for other copolymers) along with narrow $\operatorname{MWD}\left(\bigoplus_{\mathrm{M}}=1.6-2.9\right)$ allowed for the consideration of all copolymers obtained as UHMW polyolefins suitable for DR studies.

Lower yields of P1 and P2 in comparison with copolymers of linear $\alpha$-olefins P1c and $\mathbf{P} 2 \mathbf{c}$ can be attributed to the presence of inactive olefins (5-methylenenonane, internal decenes) and low-active $\alpha$-olefins (4-vinyloctane, 4-ethyl-1-octene) in starting oligomerizates M1 and M2. The presence of these olefins was detected by ${ }^{1} \mathrm{H}$ NMR spectroscopy of the final reaction mixtures (see Figures S5 and S7 in the Supplementary Materials).

${ }^{13} \mathrm{C}\left\{{ }^{1} \mathrm{H}\right\}$ NMR spectra of $\mathbf{P 1}$ and $\mathbf{P 2}$ have confirmed insertion of branched decenes. Comparison of the spectrum of P2c (Figure 2b, with identification of all signals using schematic reference spectra of isotactic poly(1-hexene), poly(1-octene) and poly(1-decene), presented in Figure 2a) with the spectrum of P2 (Figure 2c) demonstrates the absence of the signals of poly(1-decene) in the spectrum of P2. However, the spectrum of P2 contained marked characteristic signals of $>\mathrm{CHCH}_{3}$ groups $(\delta=20 \mathrm{ppm})$ and subtle signal of $>\mathrm{CHCH}_{2} \mathrm{CH}_{3}$ groups $(\delta=11 \mathrm{ppm})$ related to the products of the insertion of 5 -methyl1-nonene and 4-ethyl-1-octene, respectively. The signal of $>\mathrm{CHCH}_{3}$ groups $(\delta=20 \mathrm{ppm})$ can also be seen in ${ }^{13} \mathrm{C}\{1 \mathrm{H}\}$ NMR spectrum of P1 (see Figure S9 in the Supplementary Materials). ${ }^{13} \mathrm{C}\left\{{ }^{1} \mathrm{H}\right\}$ NMR spectra of P1 and P2 (see Section S2 in the Supplementary Materials) revealed a number of low-intensity signals, related to the products of the insertion of branched C10 $\alpha$-olefins.

However, the relative intensities of these new signals were substantially lower than the signals of the fragments, related to 1-decene insertion, in the spectra of copolymers P1c (Figure 2b) and P2c. In this way, the insertion of branched C10 $\alpha$-olefins seemed incomplete. This latter conclusion was of particular interest focusing attention on the impact of the lower amounts of branched higher $\alpha$-olefins on DR efficiency of the copolymers.

\subsection{Drag Reducing Efficiency}

Polymer samples, obtained by bulk polymerization, dissolve slowly in aliphatic hydrocarbons. Since intensive mixing can lead to the destruction of macromolecules and a decrease in the drag reducing effect, polymer solutions in $n$-heptane were made by dissolving polymer samples with slow stirring for 1 day. Various experimental methods can be used to investigate the drag reducing effect, including rotational rheometry at high Reynolds numbers [1,9,58-60] and turbulent flow rheometry [14,61]. In the present work, comparative studies of the DR efficiency of polymers $\mathbf{P H}-\mathbf{P} 2 \mathbf{c}$ were carried out at 7 and $22{ }^{\circ} \mathrm{C}$ using turbulent capillary rheometry [14] of heavily diluted polymer solutions (see Section 2.6). The chosen test temperatures correspond to average temperatures of oil and petroleum products during pipeline transportation in the winter and summer seasons, respectively [23]. The results of the measurements as dependences of DR on the polymer concentration for the second passage of the DRA solution through the rheometer tube are presented in Figure 3.

As can be seen in Figure 3, poly(1-hexene) PH, as well as copolymers P1 and P1c, demonstrated lower DR effect at lower temperature. For copolymers P2 and P2c, DR curves for different temperatures have been found to be closely aligned. DR efficiencies of all pre-prepared polymer solutions were close for $4-8$ ppm concentrations. Perhaps the most significant observation was the highest DR efficiency of the copolymer P2 at $7{ }^{\circ} \mathrm{C}$ in 1 ppm concentration ( $20 \%$ vs. $\sim 15 \%$ for all other polymers). The value of DR of $20 \%$ is characteristic for real pipeline transportation of light petroleum products using DRA dispersions; however, poly(1-hexene) DRAs fail to reach even $10 \%$ efficiency at $5-7^{\circ} \mathrm{C}$ [23]. 


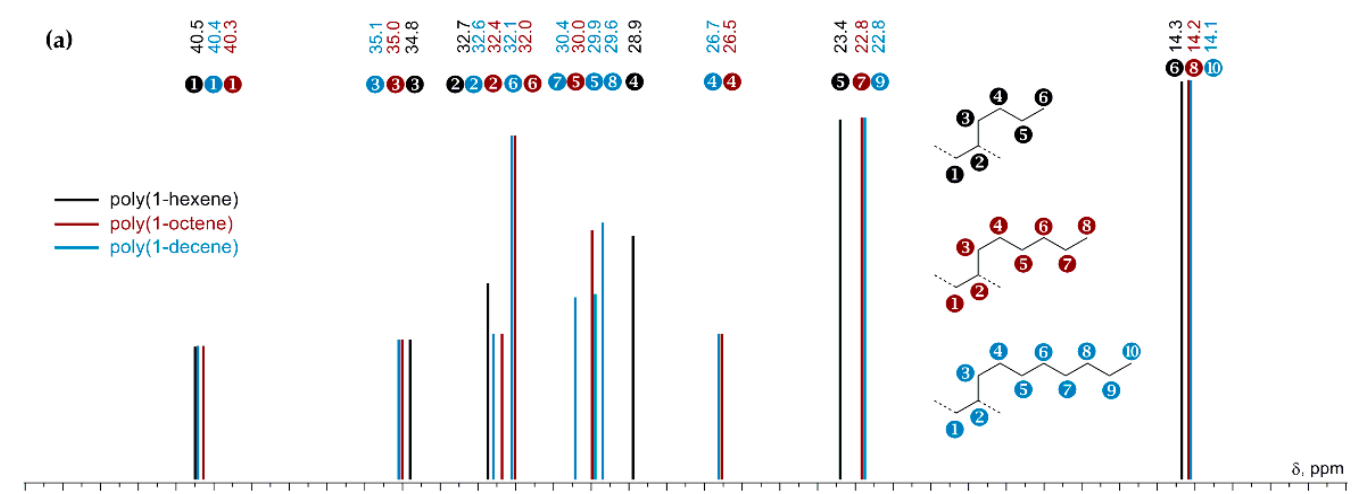

$\begin{array}{llllllllllllllllllllllllllllllllllll}45 & 44 & 43 & 42 & 41 & 40 & 39 & 38 & 37 & 36 & 35 & 34 & 33 & 32 & 31 & 30 & 29 & 28 & 27 & 26 & 25 & 24 & 23 & 22 & 21 & 20 & 19 & 18 & 17 & 16 & 15 & 14 & 13 & 12 & 11 & 10\end{array}$

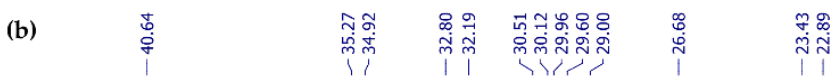
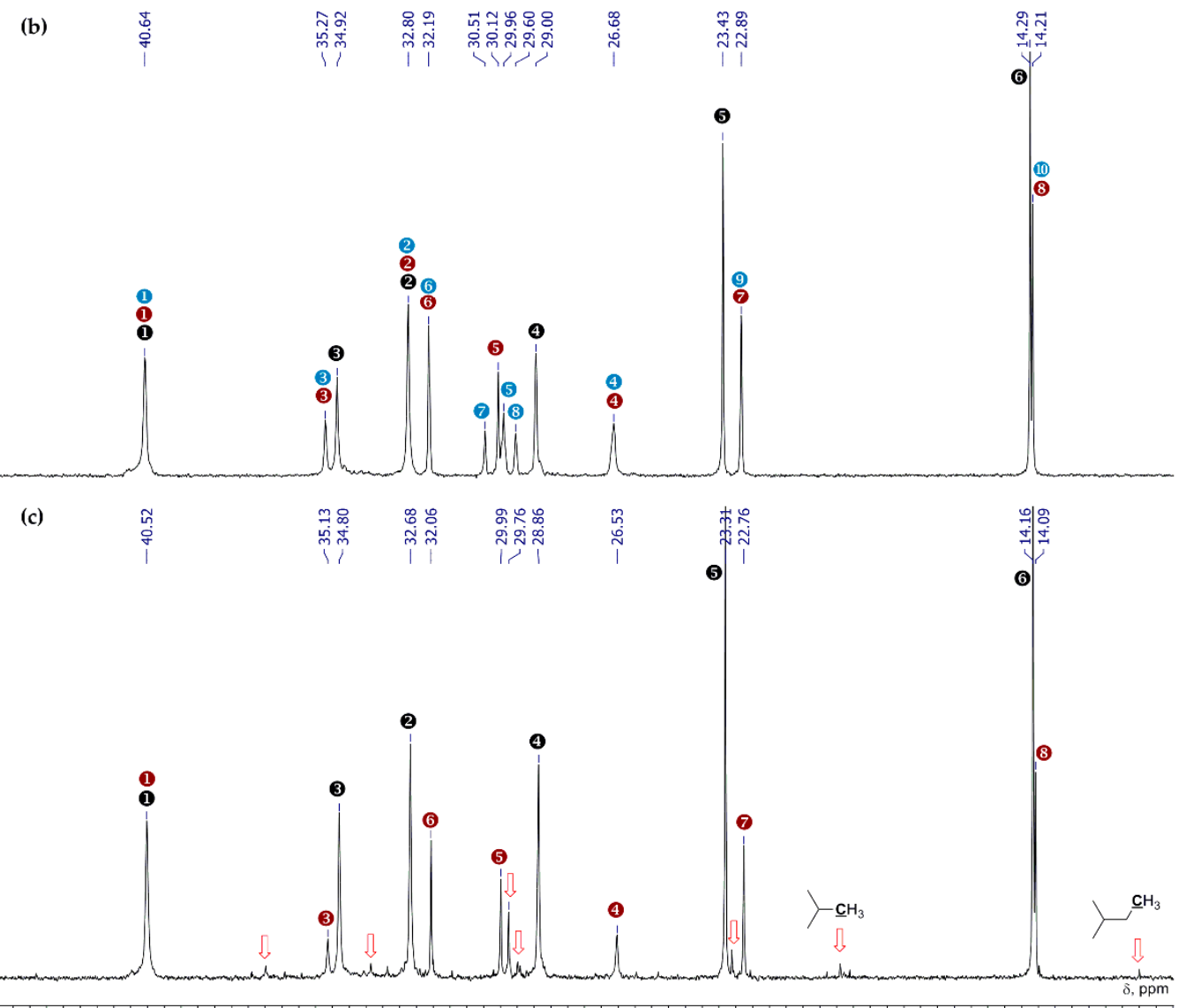

$\begin{array}{llllllllllllllllllllllllllllllllllll}45 & 44 & 43 & 42 & 41 & 40 & 39 & 38 & 37 & 36 & 35 & 34 & 33 & 32 & 31 & 30 & 29 & 28 & 27 & 26 & 25 & 24 & 23 & 22 & 21 & 20 & 19 & 18 & 17 & 16 & 15 & 14 & 13 & 12 & 11 & 10\end{array}$

Figure 2. (a) Schematic reference ${ }^{13} \mathrm{C}\left\{{ }^{1} \mathrm{H}\right\}$ NMR spectra of isotactic poly(1-hexene), poly(1-octene), and poly(1-decene) $\left({ }^{13} \mathrm{C}\left\{{ }^{1} \mathrm{H}\right\}\right.$ NMR spectra of these homopolymers are presented in Figure S4 in the Supplementary Materials); ${ }^{13} \mathrm{C}\left\{{ }^{1} \mathrm{H}\right\} \mathrm{NMR}$ spectra $\left(\mathrm{CDCl}_{3}, 50^{\circ} \mathrm{C}, 101 \mathrm{MHz}\right)$ of the copolymers $\mathbf{P 2 c}(\mathbf{b})$ and $\mathbf{P} 2(\mathbf{c})$. New signals in spectrum of $\mathbf{P} 2$ are pointed by red arrows. 

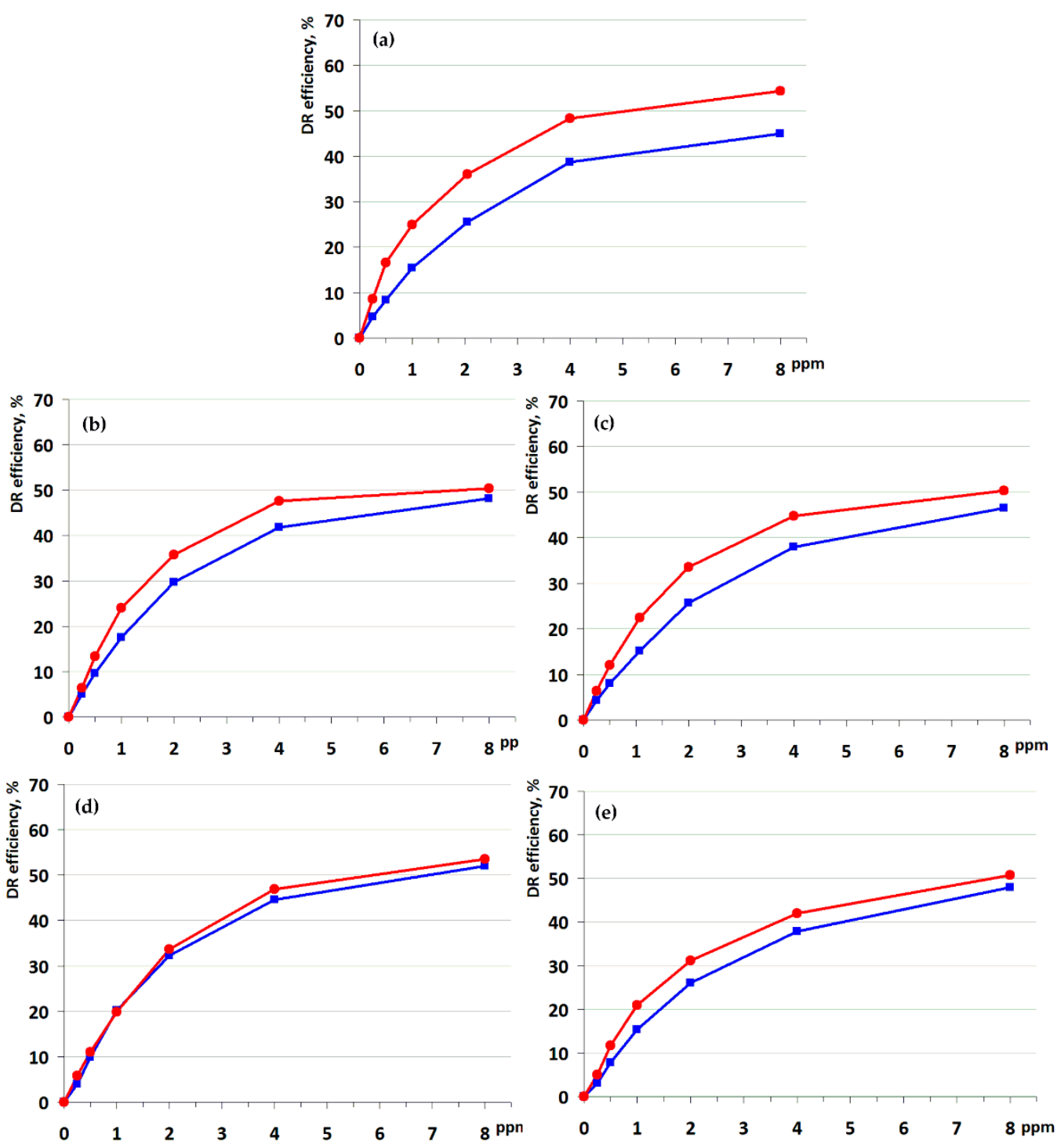

Figure 3. Dependence of the DR effect on the concentration for solutions of polymers PH (a), P1 (b), P1c (c), P2 (d), and P2c (e), in $n$-heptane at $7{ }^{\circ} \mathrm{C}$ (blue lines) and at $22{ }^{\circ} \mathrm{C}$ (red lines). Capillary turbulent flow rheometry data, the average of the three measurements for each point.

We think that the difference in low temperature DR efficiency of $\mathbf{P} \mathbf{2}$ and other polymers can be attributed to more efficient solvation of P2. Based on acoustic measurements of the solvation numbers and of DR efficiency, Brostow et al. have shown that the solvation numbers go symbiotically with that efficiency [7]. In other words, the solvated polymer domains in good solvents are larger and, therefore, more effective as DRAs. The effect of the temperature on DR efficiency of polyolefin DRAs can be explained by this factor: more regular poly(1-hexene) $\mathbf{P H}$ as well as 1-hexene enriched copolymers P1 and P1c are poorly solvated at lower temperatures, while copolymer P2, which has a less ordered microstructure due to the presence of the higher content of branched alkyl groups, retains its capacity for solvation.

The effectiveness of DRAs in real-world operation is determined by the following factors: the value of DR efficiency, the rate of solubility to achieve efficient concentration of DRA, and the rate of polymer degradation. Increasing the length of the polymer chain results in an increase inboth DR effect [14-17,62] and polymer degradation rate [63-65], and decreases the rate of solubility [14]. As was shown by Moussa and Tiu [66], most of the degradation takes place at the region of the entrance of DRAs because of the high 
extensional straining of polymer molecules; therefore, slow solubility and limited solvation increase the probability of the polymer chain scission.

The results of our comparative study of the DR efficiency of poly(1-hexene) PH, 1hexene enriched copolymers P1 and P1c, and copolymers, containing substantial amounts of 1-octene and decenes P2 and P2c, allow us to explain the loss of the DR efficiency of poly(1-hexene) DRAs at low temperature by lower dissolution/solvation rates along with relatively high degradation rates-with the result that efficient concentration of UHMW additive is simply not reached. In this way, copolymers P1 and P2 that represent the products of tandem, ethylene-based process, seem more prospective as low-temperature polyolefin DRAs.

\section{Conclusions}

In the present work, we have demonstrated the principle possibility of the 'tandem' synthesis of UHMV polyolefin DRAs by ethylene oligomerization, catalyzed by Cr-PNP complexes, followed by low-temperature polymerization of the oligomerizate, catalyzed by efficient titanium-magnesium $\mathrm{ZN}$ catalyst. For the oligomerization stage, we have shown the preference of the use of $\alpha$-olefins as a reaction media. In particular, catalyst Cr-L1 demonstrated higher activities in $\alpha$-olefins compared with $n$-heptane. In addition, the oligomerizates contained minimal amounts of inert solvents, thus providing their use as a comonomer feed for subsequent polymerization without any additional treatment.

Two oligomerizates M1 and M2 were synthesized in 1-hexene using highly selective trimerization catalyst Cr-L1 and tri/tetramerization catalyst Cr-L2. GC analysis of the oligomerizates showed the presence of branched C10 $\alpha$-olefins. UHMW polyolefins were obtained from oligomerizates M1 and M2, model mixtures of linear $\alpha$-olefins M1c and M2c, and 1-hexene. During the study of DR efficiency of copolymers we found that copolymer P2, obtained by tandem process using Cr-L2 catalyst at oligomerization stage, had the highest value of low-temperature DR efficiency at low concentrations ( 1 ppm). We propose that this was due to irregular microstructure of $\mathbf{P 2}$, the presence of $\mathrm{C} 6$ and branched $\mathrm{C} 8$ side chains, resulting in an increase in dissolution rate and solvation number. We propose that low efficiency of poly(1-hexene) DRAs at low temperatures can be attributed to inaccessibility of minimum essential polymer concentrations due to low solubility/solvation rates and relatively high degradation rates.

Therefore, the product of the tandem process represent the best choice among UHMW hydrocarbon-soluble polymers for low-temperature transportation of light petroleum products. Conditions are thus created for the further research and development of ethylenebased technology of the production of 'winter' poly- $\alpha$-olefin DRAs.

Supplementary Materials: The following are available online at https:/ /www.mdpi.com/article/ 10.3390/polym13223930/s1, Figure S1: ${ }^{1} \mathrm{H}$ NMR spectrum $\left(400 \mathrm{MHz}, \mathrm{CDCl}_{3}, 20{ }^{\circ} \mathrm{C}\right)$ of 2-ethyl-2(methoxymethyl)hexan-1-ol (main fraction, B. p. $90-110{ }^{\circ} \mathrm{C} / 16 \mathrm{mbar}$ ), Figure S2: ${ }^{1} \mathrm{H}$ NMR spectrum $\left(400 \mathrm{MHz}, \mathrm{CDCl}_{3}, 20^{\circ} \mathrm{C}\right.$ ) of BMMH, Figure S3: $\left.{ }^{13} \mathrm{C}_{\{}{ }^{1} \mathrm{H}\right\}$ NMR spectrum $\left(101 \mathrm{MHz}, \mathrm{CDCl}_{3}, 20^{\circ} \mathrm{C}\right)$ of BMMH, Figure S4: Reference ${ }^{13} \mathrm{C}\left\{{ }^{1} \mathrm{H}\right\}$ NMR spectra $\left(\mathrm{CDCl}_{3}, 50{ }^{\circ} \mathrm{C}\right)$ of isotactic poly $(1$-hexene), poly(1-octene) and poly(1-decene) (top, middle and bottom, respectively), Figure S5: ${ }^{1} \mathrm{H}$ NMR spectrum $\left(\mathrm{CDCl}_{3}, 50{ }^{\circ} \mathrm{C}\right)$ of P1, Figure S6: ${ }^{1} \mathrm{H}$ NMR spectrum $\left(\mathrm{CDCl}_{3}, 50{ }^{\circ} \mathrm{C}\right)$ of P1c, Figure S7: ${ }^{1} \mathrm{H}$ NMR spectrum $\left(\mathrm{CDCl}_{3}, 50^{\circ} \mathrm{C}\right)$ of $\mathbf{P 2}$, Figure S8: ${ }^{1} \mathrm{H}$ NMR spectrum $\left(\mathrm{CDCl}_{3}, 50^{\circ} \mathrm{C}\right)$ of P2c, Figure S9: ${ }^{13} \mathrm{C}\left\{{ }^{1} \mathrm{H}\right\}$ NMR spectrum $\left(\mathrm{CDCl}_{3}, 50{ }^{\circ} \mathrm{C}\right)$ of $\mathbf{P 1}$, Figure $\mathrm{S} 10:{ }^{13} \mathrm{C}\left\{{ }^{1} \mathrm{H}\right\}$ NMR spectrum $\left(\mathrm{CDCl}_{3}, 50{ }^{\circ} \mathrm{C}\right)$ of P1c, Figure S11: ${ }^{13} \mathrm{C}\left\{{ }^{1} \mathrm{H}\right\}$ NMR spectrum $\left(\mathrm{CDCl}_{3}, 50{ }^{\circ} \mathrm{C}\right)$ of P2, Figure S12: ${ }^{13} \mathrm{C}\left\{{ }^{1} \mathrm{H}\right\}$ NMR spectrum $\left(\mathrm{CDCl}_{3}, 50^{\circ} \mathrm{C}\right)$ of $\mathbf{P 2}$.

Author Contributions: Conceptualization, I.E.N.; methodology, I.E.N., A.N.T., G.A.A. and P.V.I.; software, R.S.B.; validation, I.E.N., A.N.T., A.A.V., G.A.A. and P.V.I.; formal analysis, R.S.B. and P.V.I.; investigation, A.N.T., A.A.V., S.A.K., M.S.C., R.S.B. and G.A.A.; resources, I.E.N.; data curation, P.V.I.; writing—original draft preparation, I.E.N. and P.V.I.; writing—review and editing, I.E.N. and P.V.I.; visualization, P.V.I.; supervision, I.E.N.; project administration, I.E.N.; funding acquisition, I.E.N. All authors have read and agreed to the published version of the manuscript. 
Funding: This research was funded by Russian Science Foundation, grant number 21-73-30010, and was carried out within the State Program of TIPS RAS (in part of polymer analysis).

Institutional Review Board Statement: Not applicable.

Informed Consent Statement: Not applicable.

Data Availability Statement: The data presented in this study are available on request from the corresponding author.

Acknowledgments: The authors are grateful for the exploitation of the equipment of the TIPS RAS Center of Collective Use: "New petrochemical processes, polymer composites and adhesives".

Conflicts of Interest: The authors declare no conflict of interest.

\section{References}

1. Brostow, W. Drag reduction in flow: Review of applications, mechanism and prediction. J. Ind. Eng. Chem. 2008, 14, 409-416. [CrossRef]

2. Wang, Y.; Yu, B.; Zakin, J.L.; Shi, H. Review on drag reduction and its heat transfer by additives. Adv. Mechan. Eng. 2011, 3 478749. [CrossRef]

3. Cuenca, F.G.; Marín, M.G.; Díaz, M.B.F. Energy-Savings Modeling of Oil Pipelines That Use Drag-Reducing Additives. Energy Fuels 2008, 22, 3293-3298. [CrossRef]

4. Toms, B.A. Some observations on the flow of linear polymer solutions through straight tubes at large Reynolds numbers. In Proceedings of the First International Congress on Rheology, Scheveningen, The Netherlands, 21-24 September 1948; Burgers, J.M., Ed.; North Holland Publishing Co.: Amsterdam, The Netherlands, 1949. Part 2. pp. 135-142.

5. Smith, R.E.; Tiederman, W.G. The mechanism of polymer thread drag reduction. Rheol. Acta 1991, 30, 103-113. [CrossRef]

6. Bewersdorff, H.W.; Gyr, A.; Hoyer, K.; Tsinober, A. An investigation of possible mechanisms of heterogeneous drag reduction in pipe and channel flows. Rheol. Acta 1993, 32, 140-149. [CrossRef]

7. Brostow, W.; Majumdar, S.; Singh, R.P. Drag reduction and solvation in polymer solutions. Macromol. Rapid Commun. 1999, 20, 144-147. [CrossRef]

8. Holtmyer, M.D.; Chatterji, J. Study of oil soluble polymers as drag reducers. Polym. Eng. Sci. 1980, 20, 473-477. [CrossRef]

9. Hong, C.H.; Jang, C.H.; Choi, H.J. Turbulent Drag Reduction with Polymers in Rotating Disk Flow. Polymers 2015, 7, 1279-1298. [CrossRef]

10. Abubakar, A.; Al-Wahaibi, T.; Al-Wahaibi, Y.; Al-Hashmi, A.R.; Al-Ajmi, A. Roles of drag reducing polymers in single- and multi-phase flows. Chem. Eng. Res. Des. 2014, 92, 2153-2181. [CrossRef]

11. Wang, Y. Reynolds Stress Model for Viscoelastic Drag-Reducing Flow Induced by Polymer Solution. Polymers 2019, 11, 1659. [CrossRef]

12. Choi, H.J.; Jhon, M.S. Polymer-Induced Turbulent Drag Reduction. Ind. Eng. Chem. Res. 1996, 35, 2993-2998. [CrossRef]

13. Ivchenko, P.V.; Nifant'ev, I.E.; Tavtorkin, A.V. Polyolefin Drag Reducing Agents (Review). Pet. Chem. 2016, 56, 775-787. [CrossRef]

14. Nesyn, G.V.; Sunagatullin, R.Z.; Shibaev, V.P.; Malkin, A.Y. Drag reduction in transportation of hydrocarbon liquids: From fundamentals to engineering applications. J. Petrol. Sci. Eng. 2018, 161, 715-725. [CrossRef]

15. White, C.M.; Mungal, M.G. Mechanics and prediction of turbulent drag reduction with polymer additives. Ann. Rev. Fluid Mech 2008, 40, 235-256. [CrossRef]

16. Wang, S.-N.; Graham, M.D.; Hahn, F.J.; Xi, L. Time-series and extended Karhunen-Loéve analysis of turbulent drag reduction in polymer solutions. AIChE J. 2014, 60, 1460-1475. [CrossRef]

17. Jin, S.; Collins, L.R. Dynamics of dissolved polymer chains in isotropic turbulence. New J. Phys. 2007, 9, 360. [CrossRef]

18. Mortazavi, S.M.M. Correlation of polymerization conditions with drag reduction efficiency of poly(1-hexene) in oil pipelines. Iran. Polym. J. 2016, 25, 731-737. [CrossRef]

19. Echevskaya, L.; Matsko, M.; Nikolaeva, M.; Sergeev, S.; Zakharov, V. Kinetic features of hexene-1 polymerization over supported titanium-magnesium catalyst. Macromol. React. Eng. 2014, 8, 666-672. [CrossRef]

20. Harjuhahto, H.; Virtanen, E.; Karbasi, A.K.; Rockas, L.; Liaho, T.; Karhu, E.; Eklund, M. Process for Preparing and Method of Using A Drag Reducing Agent. Patent WO0234802, 2 May 2002.

21. Tavtorkin, A.N.; Gavrilenko, I.F.; Kostitsyna, N.N.; Korchagina, S.A.; Chinova, M.S. Comparison of the Turbulent Drag Reduction Effectiveness of Polymers from Higher Olefin Monomers (Hexene, Octene, Decene, Dodecene) in the Production of Hydrodynamic Drag Reducing Agents for Transportation of Hydrocarbon Liquids. Russ. J. Appl. Chem. 2020, 93, 788-793. [CrossRef]

22. Mortazavi, S.M.M.; Ahmadjo, S.; Omidvar, M.; Zamani, M.R.; Fallahnezhad, R. Investigation into the effect of branch length of polyolefin and its statistical distribution on the flow improving performance. J. Polym. Res. 2021, 28, 24. [CrossRef]

23. Valiev, M.I.; Hasbiullin, I.I.; Kazakov, V.V. Specifics of using drag reducing additives based on polyalphaolefins at various oil temperatures. Oil Oil Prod. Pipeline Transp. Sci. Technol. 2016, 6, 32-37.

24. Kommareddi, N.S.; Ramsay, G.G.; Motler, J.F. Method of Preparing a Polymer Under Predetermined Temperature Conditions, and Apparatus Therefor. Patent US7015290, 26 August 2004. 
25. Balashov, A.V.; Rusinov, P.G.; Nifantiev, I.E. Drag-Reducing Agent and Method for Producing Same. Patent WO2016204654, 22 December 2016.

26. Atiqullah, M.; Al-Sarkhi, A.S.; Al-Thenayan, F.M.; Al-Malki, A.R.; Xu, W.; Hossaen, A. Catalyst Composition and A Process for Making Ultra High Molecular Weight Poly (Alpha-Olefin) Drag Reducing Agents. Patent US9969826, 15 May 2018.

27. Do, L.H.; Labinger, J.A.; Bercaw, J.E. Mechanistic Studies of Ethylene and $\alpha$-Olefin Co-Oligomerization Catalyzed by Chromium-PNP Complexes. Organometallics 2012, 31, 5143-5149. [CrossRef] [PubMed]

28. Gong, M.; Liu, Z.; Li, Y.; Ma, Y.; Sun, Q.; Zhang, J.; Liu, B. Selective Co-Oligomerization of Ethylene and 1-Hexene by ChromiumPNP Catalysts: A DFT Study. Organometallics 2016, 35, 972-981. [CrossRef]

29. Wass, D.F. Olefin Trimerization Using A Catalyst Comprising A Source of Chromium, Molybdenium or Tungsten and A Ligand Containing at Least One Phosphorus, Arsenic or Antimony Atom Bound to At Least One Hetero(Hydrocarbyl) Group. Patent US7141633, 28 November 2006.

30. Carter, A.; Cohen, S.A.; Cooley, N.A.; Murphy, A.; Scutt, J.; Wass, D.F. High activity ethylene trimerisation catalysts based on diphosphine ligands. Chem. Commun. 2002, 858-859. [CrossRef] [PubMed]

31. Blann, K.; Bollmann, A.; Dixon, J.; Navaling, A.; Morgan, D.; Maumela, H.; Killian, E.; Hess, F.M.; Otto, S.; Pepler, L.; et al. Tetramerization of Olefins. Patent WO2004056479, 8 July 2004.

32. Agapie, T. Selective ethylene oligomerization: Recent advances in chromium catalysis and mechanistic investigations. Coord. Chem. Rev. 2011, 255, 861-880. [CrossRef]

33. Nifant'ev, I.E.; Ivchenko, P.V.; Vinogradov, A.A.; Vinogradov, A.A.; Bagrov, V.V. The Method of Oligomerization of Ethylene in Organic Solvent Media in the Presence of Chromium Catalyst and Organoaluminium Activator. Patent RU2717241, 19 March 2020.

34. Sydora, O.L. Selective Ethylene Oligomerization. Organometallics 2019, 38, 997-1010. [CrossRef]

35. Nifant'ev, I.E.; Vinogradov, A.A.; Vinogradov, A.A.; Roznyatovsky, V.A.; Grishin, Y.K.; Ivanyuk, A.V.; Sedov, I.V.; Churakov, A.V.; Ivchenko, P.V. 5,6-Dihydrodibenzo [c,e] [1,2] azaphosphinine-based PNP ligands, Cr coordination and Cr(III) precatalysts for ethylene oligomerization. Organometallics 2018, 37, 2660-2664. [CrossRef]

36. Nifant'ev, I.E.; Shlyakhtin, A.V.; Tavtorkin, A.N.; Korchagina, S.A.; Chinova, M.S.; Vinogradov, A.A.; Vinogradov, A.A.; Roznyatovsky, V.A.; Khaidapova, D.D.; Ivchenko, P.V. The synthesis of ultra-high molecular weight poly(1-hexene)s by low-temperature Ziegler-Natta precipitation polymerization in fluorous reaction media. Polymer 2018, 139, 98-106. [CrossRef]

37. McGuinness, D.S.; Wasserscheid, P.; Keim, W.; Hu, C.; Englert, U.; Dixon, J.T.; Grove, C. Novel Cr-PNP complexes as catalysts for the trimerisation of ethylene. Chem. Commun. 2003, 334-335. [CrossRef]

38. Wass, D.F. Chromium-catalysed ethene trimerisation and tetramerization-Breaking the rules in olefin oligomerisation. Dalton Trans. 2007, 816-819. [CrossRef]

39. Zhang, J.; Wang, X.; Zhang, X.; Wu, W.; Zhang, G.; Xu, S.; Shi, M. Switchable ethylene tri-/tetramerization with high activity: Subtle effect presented by backbone-substituent of carbon-bridged diphosphine ligands. ACS Catal. 2013, 3, 2311-2317. [CrossRef]

40. Kuhlmann, S.; Blann, K.; Bollmann, A.; Dixon, J.T.; Killian, E.; Maumela, M.C.; Maumela, H.; Morgan, D.H.; Prétorius, M.; Taccardi, N.; et al. N-substituted diphosphinoamines: Toward rational ligand design for the efficient tetramerization of ethylene. J. Catal. 2007, 245, 279-284. [CrossRef]

41. van Leeuwen, P.W.N.M.; Clément, N.D.; Tschan, M.J.-L. New processes for the selective production of 1-octene. Coord. Chem. Rev. 2011, 255, 1499-1517. [CrossRef]

42. De Wet-Roos, D.; Du Toit, A.; Joubert, D.J. Homogeneous tandem catalysis of the bis-(diphenylphosphino)-amine/chromium tetramerization catalyst with metallocene catalysts. J. Polym. Sci. Part A Polym. Chem. 2006, 44, 6847-6856. [CrossRef]

43. Jiang, T.; Huang, Z.; Luo, M.; Chen, H.; Ning, Y. Preparation of ethylene/1-octene copolymers from ethylene stock with tandem catalytic system. J. Appl. Polym. Sci. 2008, 107, 3071-3075. [CrossRef]

44. van Rensburg, W.J.; van den Berg, J.-A.; Steynberg, P.J. Role of MAO in Chromium-Catalyzed Ethylene Tri- and Tetramerization: A DFT Study. Organometallics 2007, 26, 1000-1013. [CrossRef]

45. Agapie, T.; Labinger, J.A.; Bercaw, J.E. Mechanistic Studies of Olefin and Alkyne Trimerization with Chromium Catalysts: Deuterium Labeling and Studies of Regiochemistry Using a Model Chromacyclopentane Complex. J. Am. Chem. Soc. 2007, 129, 14281-14295. [CrossRef] [PubMed]

46. Peitz, S.; Aluri, B.R.; Peulecke, N.; Müller, B.H.; Wöhl, A.; Müller, W.; Al-Hazmi, M.H.; Mosa, F.M.; Rosenthal, U. An Alternative Mechanistic Concept for Homogeneous Selective Ethylene Oligomerization of Chromium-Based Catalysts: Binuclear Metallacycles as a Reason for 1-Octene Selectivity? Chem. Eur. J. 2010, 16, 7670-7676. [CrossRef]

47. Do, L.H.; Labinger, J.A.; Bercaw, J.E. Spectral studies of a $\mathrm{Cr}(\mathrm{PNP})-\mathrm{MAO}$ system for selective ethylene trimerization catalysis: Searching for the active species. ACS Catal. 2013, 3, 2582-2585. [CrossRef]

48. Britovsek, G.J.P.; McGuinness, D.S.; Wierenga, T.S.; Young, C.T. Single- and Double-Coordination Mechanism in Ethylene Tri- and Tetramerization with Cr/PNP Catalysts. ACS Catal. 2015, 5, 4152-4166. [CrossRef]

49. Dixon, J.T.; Green, M.J.; Hess, F.M.; Morgan, D.H. Advances in selective ethylene trimerization-A critical overview. J. Organomet. Chem. 2004, 689, 3641-3668. [CrossRef]

50. McGuinness, D.S. Olefin Oligomerization via Metallacycles: Dimerization, Trimerization, Tetramerization, and Beyond. Chem. Rev. 2011, 111, 2321-2341. [CrossRef] 
51. Alferov, K.A.; Belov, G.P.; Meng, Y. Chromium catalysts for selective ethylene oligomerization to 1-hexene and 1-octene: Recent results. Appl. Catal. A Gen. 2017, 542, 71-124. [CrossRef]

52. Terano, M.; Soga, H.; Kimura, K. Catalyst for Polymerization of Olefins. Patent US4829037, 9 May 1989.

53. Zhang, R.; Tan, Z.; Zhou, Q.; Xu, X.; Yin, S.; Li, F.; Song, W.; Yu, J. Catalyst Component for Olefin Polymerization, Preparation Method Thereof, and Catalyst Comprising Same. Patent CN107344976, 14 November 2017.

54. Morini, G.; Albizzati, E.; Balbontin, G.; Mingozzi, I.; Sacchi, M.C.; Forlini, F.; Tritto, I. Microstructure Distribution of Polypropylenes Obtained in the Presence of Traditional Phthalate/Silane and Novel Diether Donors: A Tool for Understanding the Role of Electron Donors in $\mathrm{MgCl}_{2}$-Supported Ziegler-Natta Catalysts. Macromolecules 1996, 29, 5770-5776. [CrossRef]

55. Denkwitz, Y.; Schuster, O.; Winter, A. High Performance Ziegler-Natta Catalyst Systems, Process for Producing Such Supported Catalysts and Use Thereof. Patent US9481741, 1 November 2016.

56. Agnes, G.; Borsotti, G. Diethers Usable in the Preparation of Ziegler-Natta Catalysts and Their Preparation. Patent EP0361493, 4 April 1990.

57. Borsotti, J. Process for the Preparation of Diethers. Patent EP0487035, 27 May 1992.

58. Pereira, A.S.; Soares, E.S. Polymer degradation of dilute solutions in turbulent drag reducing flows in a cylindrical double gap rheometer device. J. Nonnewton. Fluid Mech. 2012, 179-180, 9-22. [CrossRef]

59. Eskin, D. Applicability of a Taylor-Couette device to characterization of turbulent drag reduction in a pipeline. Chem. Eng. Sci. 2014, 116, 275-283. [CrossRef]

60. Guersoni, V.C.B.; Bannwart, A.C.; Destefani, T.; Sabadini, E. Comparative Study of Drag Reducers for Light Hydrocarbon Flow. Pet. Sci. Technol. 2015, 33, 943-951. [CrossRef]

61. Kim, C.A.; Lee, K.; Choi, H.J.; Kim, C.B.; Kim, K.Y.; Jhon, M.S. Universal Characteristics of Drag Reducing Polyisobutylene in Kerosene. J. Macromol. Sci. A Pure Appl. Chem. 1997, 34, 705-711. [CrossRef]

62. Kouser, T.; Xiong, Y.; Yang, D. Contribution of Superhydrophobic Surfaces and Polymer Additives to Drag Reduction. ChemBioEng Rev. 2021, 8, 337-356. [CrossRef]

63. Horn, A.F.; Merrill, E.W. Midpoint scission of macromolecules in dilute solution in turbulent flow. Nature 1984, $312,140-141$. [CrossRef]

64. Zhang, X.; Duan, X.; Muzychka, Y. Degradation of flow drag reduction with polymer additives-A new molecular view. J. Mol. Liq. 2019, 292, 111360. [CrossRef]

65. Soares, E.J. Review of mechanical degradation and de-aggregation of drag reducing polymers in turbulent flows. J. Non-Newton. Fluid Mech. 2020, 276, 104225. [CrossRef]

66. Moussa, T.; Tiu, C. Factors affecting polymer degradation in turbulent pipe flow. Chem. Eng. Sci. 1994, 49, 1681-1692. [CrossRef] 